\title{
Are sports medicine journals relevant and applicable to practitioners and athletes?
}

\author{
C Bleakley, D MacAuley, S McDonough
}

Br J Sports Med 2004;38:e23 (http://www.bjsportmed.com/cgi/content/full/38/5/e23). doi: 10.1136/bjsm.2003.010553

Objective: To examine the evidence base of sports medicine research and assess how relevant and applicable it is to everyday practice.

Methods: Original research articles, short reports, and case reports published in four major sport and exercise medicine journals were studied and classified according to the main topic of study and type of subjects used.

Results: The most common topic was sports science, and very few studies related to the treatment of injuries and medical conditions. The majority of published articles used healthy subjects sampled from the sedentary population, and few studies have been carried out on injured participants.

Conclusions: There is a dearth of studies addressing diagnostic and treatment interventions in the sports medicine literature. The evidence base for sports medicine must continue to increase in terms of volume and quality.

n evidence based medicine, we expect the research literature to be relevant to patients whom we treat. In

sports and exercise medicine we assume that our subjects are active athletes. One major criticism of evidence based medicine is that it is difficult to apply in the real world. It is important, therefore that research driving, evidence based practice in sports and exercise medicine is relevant to our patients.

Previous studies ${ }^{12}$ of the evidence base for sports medicine assessed the quality of methods used in research articles, and although the number of randomised controlled trials in sports medicine has increased over the past 10 years most studies are still observational. ${ }^{2}$ The relevance and applicability are also important for clinicians selecting and appraising published reports. ${ }^{3}$ In Thompson's review, ${ }^{1}$ the largest group of papers $(20.9 \%)$ was of sports science, with fewer studies of medical conditions and diagnostic investigations. Indeed he questioned how relevant some of the studies were to sports medicine practice.

We have examined the quality of the research methods in previously published reports. In this study our aim was to further examine the evidence base of sports medicine research to see how relevant and applicable it is to everyday practice. The specific objectives were to look at the subjects used and the nature of research in published papers in key sports medicine journals from 1996 to 2000.

\section{METHODS}

We studied original research articles, short reports, and case reports published in four major sport and exercise medicine journals in the five year period from 1996 to 2000 inclusive. Contents were classified according to the main topic of study, using criteria modified from Thompson's audit report, ${ }^{1}$ and we looked particularly at the subjects of all observational, quasi-experimental, and experimental studies.

\section{RESULTS}

There were 1602 original articles, short reports, and case reports, classified into the various groups (tables 1 and 2). In three journals the most common topic was sports science, which comprised $21.2 \%, 56.6 \%$, and $58.2 \%$ of the articles published in Br J Sports Med, J Sports Med Phys Fitness, and Int J

Table 1 Topics covered four major international sports medicine journals

\begin{tabular}{lllll}
\hline Topic & $\begin{array}{l}\text { Br J Sports } \\
\text { Med }\end{array}$ & $\begin{array}{l}\text { J Sports Med } \\
\text { Phys Fitness }\end{array}$ & $\begin{array}{l}\text { Int J Sports } \\
\text { Med }\end{array}$ & $\begin{array}{l}\text { Am J Sports } \\
\text { Med }\end{array}$ \\
\hline Injury incidence & $47(17.1)$ & $9(4.4)$ & $14(2.9)$ & $56(8.7)$ \\
Psychology/psychiatry & $11(3.9)$ & $8(3.9)$ & $4(0.8)$ & $0(0)$ \\
Injury prevention & $11(3.9)$ & $0(0)$ & $2(0.4)$ & $21(3.2)$ \\
Diagnostic & $23(8.2)$ & $15(7.4)$ & $37(7.9)$ & $51(7.9)$ \\
Treatment of injury/medical condition & $9(8.2)$ & $5(2.5)$ & $6(1.3)$ & $115(17.8)$ \\
Anatomy/biomechanics/anthropometry & $14(4.6)$ & $16(7.7)$ & $28(5.9)$ & $97(15.0)$ \\
Drugs & $10(3.6)$ & $3(1.4)$ & $23(4.9)$ & $4(0.6)$ \\
Nutrition & $3(1.1)$ & $8(3.9)$ & $33(7.1)$ & $0(0)$ \\
Physical activity/health promotion & $12(4.3)$ & $3(1.5)$ & $7(1.5)$ & $0(0)$ \\
Case reports of rare injuries & $50(17.1)$ & $6(2.9)$ & $12(2.6)$ & $70(10.8)$ \\
Anatomical/biomechanical & & & & \\
physiological evaluation of subjects & $10(3.6)$ & $6(2.9)$ & $22(4.7)$ & $107(16.5)$ \\
with injuries/medical condition & $7(2.5)$ & $0(0)$ & $2(0.4)$ & $10(1.5)$ \\
Sports equipment & $62(22.1)$ & $115(56.6)$ & $272(58.2)$ & $37(5.7)$ \\
Sports science & $0(0)$ & $0(0)$ & $0(0)$ & $51(7.9)$ \\
Surgical tools/technique & $15(5.0)$ & $9(4.4)$ & $5(1)$ & $28(4.3)$ \\
Miscellaneous & $\mathbf{2 8 5}$ & $\mathbf{2 0 3}$ & $\mathbf{4 6 7}$ & $\mathbf{6 4 7}$ \\
Total & & &
\end{tabular}

Percentages given in brackets.

Br J Sports Med, British Journal of Sports Medicine; J Sports Med, Journal of Sports Medicine and Physical Fitness; Int J Sports Med, International Journal of Sports Medicine; Am J Sports Med, American Journal of Sports Medicine. 
Table 2 Type of subjects used in international sports medicine literature

\begin{tabular}{|c|c|c|c|c|}
\hline Subject* & Br J Sports Med & $\begin{array}{l}\text { J Sports Med Phys } \\
\text { Fitness }\end{array}$ & Int J Sports Med & Am J Sports Med \\
\hline $\begin{array}{l}\text { Healthy sedentary } \\
\text { Healthy amateur/ } \\
\text { recreational athlete } \\
\text { Healthy elite athlete } \\
\text { Injured } \\
\text { Injured elite athlete } \\
\text { Other }\end{array}$ & $\begin{array}{l}35(28) \\
25(20) \\
17(13.6) \\
0 \\
9(7.2)\end{array}$ & $\begin{array}{l}44(33.3) \\
23(17.4) \\
10(7.9) \\
1(0.8) \\
8(6.0)\end{array}$ & $\begin{array}{l}165(35.5) \\
80(17.2) \\
45(9.7) \\
5(1.1) \\
32(6.9)\end{array}$ & $\begin{array}{l}46(9.1) \\
12(2.4) \\
256(50.9) \\
13(2.6) \\
152(30.2)\end{array}$ \\
\hline \multicolumn{5}{|c|}{$\begin{array}{l}\text { Percentages given in brackets. } \\
\text { *Type of subject in observational, quasi-experimental, and experimental studies. } \\
\text { Br J Sports Med, British Journal of Sports Medicine; J Sports Med Phys Fitness, Journal of Sports Medicine and } \\
\text { Physical Fitness; Int J Sports Med, International Journal of Sports Medicine; Am J Sports Med, American Journal of } \\
\text { Sports Medicine. }\end{array}$} \\
\hline
\end{tabular}

Sports Med, respectively. Very few studies in these journals $(\mathrm{Br}$ J Sports Med, 8.2\%; J Sports Med Phys Fitness, 2.5\%; Int J Sports Med, $1.3 \%$ ) related to the treatment of injuries and medical conditions. In comparison, many more studies in $A m J$ of Sports Med (17.8\%) were related to the treatment or management of injuries and medical conditions, with only a small percentage $(5.7 \%)$ focusing on sports science.

Both Br J Sports Med (17.1\%) and Am J Sports Med (10.8\%) reported widely on rare injuries using case reports, but there were fewer similar studies in J Sports Med Phys Fitness (2.9\%) or Int J Sports Med (1.3\%). Similarly, a much larger percentage of studies in Br J Sports Med (17.1\%) and Am J Sports Med $(8.7 \%)$ reported on injury incidence, attributed by either body part or sport, compared with J Sports Med Phys Fitness (4.4\%) and Int J Sports Med (2.9\%). The proportion of studies focusing on diagnostic intervention was consistent across journals, comprising $8.2 \%, 7.4 \%, 7.9 \%$, and $7.9 \%$ of all studies reported in Br J Sports Med, J Sports Med Phys Fitness, Am J Sports Med, and Int J Sports Med, respectively.

A significant majority of studies in Br J Sports Med (79.2\%), $J$ Sports Med Phys Fitness (88.6\%), and Int J of Sports Med $(80.2 \%)$ used healthy subjects. Most of these healthy subjects were sampled from the sedentary population, with fewer healthy amateur athletes, and even fewer elite athletes involved. A much smaller percentage of studies in Am J Sports Med used healthy subjects (16.3\%); the majority of studies published in that journal used injured participants (53.5\%). In contrast, in Br J Sports Med and Int J Sports Med, only $13.6 \%$ and $10.8 \%$ of studies, respectively, were undertaken on injured subjects, and few of these were athletes performing at an elite level. Even fewer studies in J Sports Med Phys Fitness (7.9\%) used injured subjects, and just one study $(0.8 \%)$ used an elite athlete with a medical condition or injury. Other studies included the elderly, disabled people, animal subjects, and cadavers.

\section{DISCUSSION}

Sports medicine is a wide ranging discipline, and its diverse nature is clearly evident in our findings. The topics covered and subjects used in these journals are, however, quite consistent. Most studies were of healthy subjects across the sporting population, ranging from recreational to elite athletes. Clinical studies using injured subjects were infrequent, and studies of the elite injured athlete were very rare. We might speculate as to the reasons why this should be. Highly motivated athletes may be unhappy to be allocated to a control group, and recruitment of elite athletes in particular into randomised controlled trials may therefore be difficult.

\section{Take home message}

The evidence base for sports medicine must continue to increase in terms of volume and quality, to truly evolve from a clinical interest group to a recognised medical specialty. This should involve employing high quality research methods, in clinical studies using injured subjects. These studies should focus on evaluating the efficacy and safety of rehabilitative and preventive regimes.

However, this creates a problem and we need to ask if we can extrapolate research findings from recreational or amateur athletes to their elite counterparts, given the unique demands of professional sport.

Practising evidence based medicine means integrating clinical expertise with the best available external evidence from research findings. ${ }^{4}$ Although the best external clinical evidence can come from basic sciences, it should ideally be derived from patient centred clinical research, studying diagnostic tests and the efficacy and safety of rehabilitative and preventive regimes. ${ }^{4}$ We found a dearth of studies addressing diagnostic and treatment interventions; it is difficult, therefore, to practice evidence based medicine when the research is not applicable. Perhaps those criticising evidence based medicine in sports and exercise medicine have some justification.

\section{Authors' affiliations}

C Bleakley, S McDonough, University of Ulster, Jordanstown, Northern Ireland, UK

D MacAuley, Hillhead Surgery, Belfast, Northern Ireland

Correspondence to: $\operatorname{Dr} S \mathrm{M} M c D o n o u g h$, University of Ulster, Jordanstown, Shore Road, Newtownabbey BT38 OQB, UK

Accepted 13 January 2004

\section{REFERENCES}

1 Thompson B. A review of the British Journal of Sports Medicine 1991-5. Br J Sports Med 1996;30:354-5.

2 Bleakley CM, MacAuley D. The quality of research in sports journals. Br J Sports Med 2002;36:124-6.

3 MacAuley D. READER : an acronym to aid critical reading by general practitioners. Br J Gen Pract 1994;44:83-5.

4 Sackett DL, Rosenberg WMC, Muir Grey JA, et al. Evidence based medicine: what it is and what it isn't. BMJ 1996;312:71-2. 